"The EUrASEANs: journal on global socio-economic dynamics"

Volume 6 (25); November - December, Year 2020;

ISSN $2539-5645$ (Print)

Copyright $\mathbb{C}$ 2020, [The EUrASEANs]

on-line access: https://www.euraseans.com/6(25)

All issues of this journal are alternatively stored and archived by: the National Library of Thailand, Russian E-library and Index Copernicus library of journals, Poland

\title{
HOW EFFECTIVE ARE ESL GAMES COMPARED TO TRADITIONAL LEARNING
}

\author{
Robert Heathfield
}

\author{
Suan Sunandha Rajabhat University, Bangkok, Thailand
}

The aim of this research was to discover the effectiveness of educational games in acquiring vocabulary and conversation skills while learning English as a second language (ESL) in Thai context. The study sought to examine how games and activities aided ESL learners in retaining vocabulary and engaging in role play activities. Educational games enable learners to acquire vocabulary and the relevant context subconsciously while they are engaged in seemingly non-academic activities. The result of using games and activities in the classroom is the creation of a playful atmosphere which makes the teaching-learning process more engaging and thus also makes the learning experience more enjoyable for both the learner and the teacher. The data was collected from six ESL classes totaling 160 learners from the SSRUIC Airline Business major. Evaluation checklist and survey questionnaires were selected as the research tools. The analysis of the data collected revealed that games could indeed accustom learners with new words and phrases and thus aid in deep-seated retention of vocabulary in a better, faster and more engaging way in comparison to memorization or standard textbook study. Games also help develop learners' communicative abilities. Most of the learners interviewed recognized that the game-based methods have their advantages and benefits in terms of improving vocabulary and conversation skills. However, to overcome certain limitations, the researcher suggests further study in this direction.

Keywords: educational games; language games; vocabulary; ESL; Thailand

\section{Introduction}

Vocabulary, phrasal verbs and conversation skills are vital in everyday English as well as in academic communication. Their value is clearly seen even at the outset of the learning process for learners of English as a second language. In this context, vocabulary and conversation skills are some of the fundamental aspects of language ability as they reflect how well learners can perform in the four major areas of communication - listening, speaking, reading and writing. The language capability of learners can be enhanced by developing their vocabulary and conversation skills (Ellis, 1997). The importance of

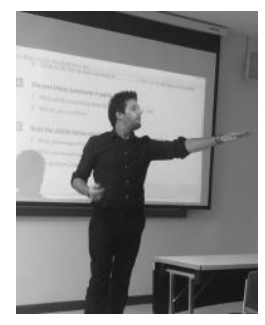

Robert Heathfield

Master of Arts

Lecturer in International College, Suan Sunandha Rajabhat University, Thailand.

Research interests: education technologies, linguistic, cooperative learning

E-mail: rober.he@ssru.ac.th 
vocabulary retention is crucial as vocabulary learning is often considered an arduous and tedious process. There are many varied approaches that have been introduced over the years to help ESL learners develop and learn vocabulary and acquire conversation skills, i.e., watching English-speaking TV channels or films with subtitles, listening to English music, reading books or newspapers, watching vlogs on YouTube, using phone applications, playing web-based and mobile games, etc. Using games as a teaching and learning method is very popular in many countries around the world.

Although, it seems that within Thai education system, vocabulary and conversation skills, teaching and learning belong to the most neglected areas of the ESL process. Inadequate knowledge of sentence structures and vocabulary is considered as one of the major problems in learning the language. Teachers mostly teach Grammar formulas to be memorized thus teaching English without using even a single language activity. As a result, learners understandably get bored and lose interest in the learning process as such. As memorization is the main learning method, motivation decreases in the classroom.

This study explores the effectiveness of using games as a vocabulary and conversation skills teaching technique in the classroom in SSRUIC. This interesting method can be used for facilitating vocabulary retention in other environments too.

\section{Research Questions}

This research aims to look for answers to the following questions:

1. How does the use of language games affect the retention of vocabulary and conversation skills?

2. Do games enable learners to progress more quickly in applying words in various contexts?

3. Does the use of games and activities have any effect on class discipline?

\section{Significance of the Study}

This study should be useful for ESL teachers in general and also for learners at every level, age and ability. In particular, it helps with understanding the importance of using games while teaching new words and having basic conversations with/among ESL learners. The study should also help them become accustomed with a number of methods for English language teaching and classroom strategies and inspire them to initiate a variety of activities according to the requirements of their learners. This can ensure effective classroom management as well as increase learners motivation levels during the classroom learning process (Davies \& Pearse, 2000).

\section{Literature Review}

There is a plethora of research and teaching resources that show that games and activities are an essential part of learning English as a second language. "If language structure makes up the skeleton of language, then it is vocabulary that provides the vital organs and flesh," (Lewis, 2006). Sometimes it can be difficult to comprehend a sentence spoken with some grammatical mistakes, it is almost impossible to convey anything without 


\section{HOW EFFECTIVE ARE ESL GAMES}

accurate vocabulary and so we see the importance of vocabulary over the favored grammar (Dolati \& Mikaili, 2011).

"Game has its potential as an educational tool for literary training; and can motivate and engage learners especially the quiet and passive ones in the whole learning process" (Huyen \& Nga, 2003).

Vocabulary-learning language games help and encourage ESL learners as they sustain their interest. Games result in fun and motivation for learners making them learn new items effortlessly. Some games can be quite informative and enlightening too. Educational language games play a vital role in learning basic language skills. Games area "form of play governed by rules." However, they can be relished only if they are entertaining (Byrne, 1987). They should not turn out to be a heavy preoccupation; rather provide a break from routine exercises, making learners utilize the language as amusement.

Likewise, Hadfield, J. (1990) labels language games as a blend of rules and fun aimed to achieve a goal. There are many types of language games that can be used according to the level of learners. Whereas learners may learn language significantly and effectively via games (Hunt \& Beglar, 2002), positive criticisms from teachers or learners can help both to adapt the classroom based on needs' analysis. They can measure in real time whether learning objectives were achieved or not, without any outside review or input.

\section{Research Methodology}

For this procedure Kurt Lewin's action research process was used by the researcher. To measure the effectiveness of learning vocabulary and conversation skills through games, several games were applied and where necessary adapted to examine whether and how games could aid learners in learning vocabulary and getting conversation skills in an adequate manner. The researcher used a selection of simple language games and activities like cataloging, elimination, sign your name, name ten, charades, draw it and pigeonhole in the chosen classes, the details of which are as follows:

Catalogue Game. The teacher divides learners into four groups, and each group is supposed to write down as many words (either on paper, or on white board) as they could remember from the unit covered that day. The team with the higher number of words wins. This game requires pens and papers, or a board and board markers. Also, this game get the learners animated when a countdown clock is used.

Elimination Game. The class is divided into four groups, and each group of learners forms a line. The teacher lists the vocabulary words or phrases randomly on the white board. When the game begins, each group of learners pronounces and defines the word or phrase. If they did it correctly, the word or phrase gets erased from the board. The team that has erased the most words or phrases first, wins. This game requires a board and board markers only.

Sign Your Name Game. The class is divided into two groups to form two circles, inner and outer one. In each circle, one learner asks a question from the learner facing him/her on their turn and on a correct answer is then signed on his/her sheet. The team with most signatures wins. The materials required for this game are paper and pens/pencils.

Name Ten (Cheeky Monkey). The class is divided into four groups. The teacher sets a topic or a category and the learners write ten words related to this topic as quickly as they can. The first group to write ten correctly related words shouts 'Cheeky Monkey' to get a 
point. The team with most points wins. The materials required include paper and pens (or a whiteboard and markers).

Charades. The class is divided into four groups. A member from each group comes to the front and shows the word or phrase picked from a basket. The other group tries to guess the word or phrase being demonstrated to them. When guessing correctly, each team gets a point and then the team with the most points wins. The materials required for this game include a basket and small pieces of paper.

Draw It. The class is divided into four groups. Each learner of the group comes up to the front, picks a card with a word from a hat and then draws a representation of this word or phrase on a board. The team with the right guess gets a point, and the team with most points wins. The materials required for the game are a hat, pieces of paper, a board and markers.

Pigeonhole. The teacher writes word groups on the board and the learners have to organise the words into correct pigeonholes according to the topics discussed earlier in class. The team with most correct words in each category wins. The materials required for the game are pens, paper, board and board markers.

While several games were inserted into each lesson plan, the researcher observed and recorded the learner's reactions and emotions for each activity. The instruments used were questionnaires, interviews and post-game surveys.

The analysis is qualitative in nature. The population of the study consists of several English Language classes, all among the SSRUIC learners in the academic year 2018-2019. The samples for this study were collected from six English ESL classes totaling to 160 learners from the SSRUIC Airline Business major.

\section{Results}

The results are divided into two categories. The first section looks at the teacher's opinions and recordings gathered from the evaluation checklist filled in at the end of each class during the sampling period. The second section looks at the results of the survey questionnaire designed to understand the feedback from learners about the effectiveness of games for teaching vocabulary and conversation skills.

\section{Evaluation Checklist Results}

Following is the feedback of teachers about their experiences during the sample period.

Could you meet your learning objectives? It was recognized that at the end of each lesson, the learners were able to retain the definitions of words and most of the learners could successfully use vocabulary in regular spoken phrases. It was also observed that the learners could create their own sentences by using words that they had just learned during the games.

Was there adequate class time to include the games and activities and achieve your required learning outcomes? The class time was three hours. Adding games could adequately fit in the class time by using the usual recapitulation time at the end of the class with the addition of an extra activity before the 15-minute break proved a good motivation lift to each study session.

Was it easy to explain how to play the games and were the learners able to understand sufficiently enough to play the game appropriately? All the learners made a mess of each game the first time that they were explained. Thus, the learners required repeated 


\section{HOW EFFECTIVE ARE ESL GAMES}

explanations. However, once the students became familiar with how to play each game or activity, they quickly became very effective in them.

Was the vocabulary appropriate and context-based? All vocabulary was selected from the relevant textbook.

What type of behavior did you observe among the learners? Most learners were easily engaged, but some were reluctant to be involved and some started talking. Overall, most learners were happy to participate in new games and activities as well as to learn new words. They were motivated and enjoyed all the activities, especially the fun games like Name Ten or charades. It was noted that the learners particularly enjoyed the competitive aspect of the games and the countdown timer always provoked extra motivation in the learners, even those who were reluctant to be involved at the start.

Was there a problem with discipline during the game activities? During the groupwork it was observed that the environment could get messy and a little disordered but overall the learners stayed engaged. There was the odd tendency for some learners to be distracted if the games went on a little too long. This was countered by the teacher being aware and continuing to engage those learners whose attention waned.

How was the learner engagement during the activities? The learner engagement was much higher than in other classes where games were not played.

\section{Teachers' Class Survey and Interviews}

The survey from the teachers' perspective was based on the classroom observations and learner feedback interviews.

1. Use of games is a good classroom strategy to aid learners in their retention of vocabulary and getting accustomed with natural English phrases. Only $60 \%$ of the respondents strongly agreed that games helped learners increase their vocabulary and natural English phrases whereas the rest of $40 \%$ agreed to it. Overall, all the respondents agreed that games facilitated learners' vocabulary and natural English phrases' retention.

2. Games enable teachers to create appropriate and relevant language contexts. All the respondents agreed that games and activities facilitated the creation of appropriate and relevant language contexts. $100 \%$ of the surveyed were positive about this statement.

3. ESL games and activities motivate and assist learners as they maintain their focus in the classroom. $90 \%$ of the respondents strongly agreed with this statement while $10 \%$ agreed with the statement. Almost all the learners interviewed found games and similar activities helpful for learning new words and phrases.

4. ESL activities and games create a more motivated learning environment. $80 \%$ of the respondents strongly agreed that vocabulary games motivate learners to learn English, whereas $20 \%$ agreed to it. None of them disagreed with this statement.

5. Is the classroom disorganized and too loud because of games and activities? $40 \%$ of the respondents agreed that the classroom was disorganized and too loud because of games and activities, $40 \%$ somewhat disagreed with this statement, and $20 \%$ of the respondents strongly disagreed. Overall, most of the respondents disagreed with the statement.

6. Games and activities create a fun and relaxed environment, so learners retain information more effectively. $50 \%$ of the respondents strongly agreed that games and activities create a fun and relaxed environment; $40 \%$ somewhat agreed whereas $10 \%$ chose 
the option "undecided". Most of the respondents considered using games as being helpful for learning.

7. Using games and activities disrupts the normal flow in the classroom. $10 \%$ of the respondents agreed with this statement, $20 \%$ were undecided, $40 \%$ disagreed and finally $30 \%$ of the respondents strongly disagreed. This division shows that there were mixed views among the respondents as to using games and similar activities which are different from the usual learning experience.

\section{Learners Questionnaire Results}

All the learners who participated in this study were given a basic questionnaire in addition to those learners who were selected for an interview during the research period.

The learners' behavior was observed by the researcher and then they were asked to complete a very simple questionnaire which contained two questions only.

8. Have you played language games and activities in an ESL class before?

90\% learners were never taught with the help of language games and similar activities, thus, it was a completely new experience for them.

9. How was your experience of learning by playing games and activities?

Most of the learners found it a very good experience to learn English vocabulary and phrases through games.

\section{Discussion}

Teaching ESL in Thailand has been improving year on year for many years. Still, some English teachers are unfamiliar with many newer ELT techniques. Incorporating games and similar activities into the process of teaching vocabulary and natural English phrases in the local lesson plans has proved to be very beneficial, although it might take some extra time to adjust to this new methodology. However, once applied, the feedback was overwhelmingly positive. Time management was the main issue since combining traditional textbook teaching with a few vocabulary games in one class requires some replanning.

Some of the learners insisted on using bilingual definitions of the words, but the games made a difference and in fact caused the learners to do some peer-to-peer teaching as part of the activity. The learners remained positive and motivated about the introduction of such new activities, thus, they gave highly positive feedback. Although the percentage of the learned new words and phrases increased, the traditional order of the classroom was disturbed, especially during highly competitive activities. The traditionally silent atmosphere in classrooms got disturbed by the learners' movements like getting up, running to the board, or standing in rows and circles.

One of the most beneficial effects of using games and activities was the increased interaction amongst learners, which resulted in better communication skills as well as more friendly and competitive atmosphere. Another essential aspect of these activities was the kinesthetic factor.

The lethargy of the classroom was eliminated in two ways: first by movement as such, second by the nature of game activity itself. The activities provided a break either in the 


\section{HOW EFFECTIVE ARE ESL GAMES}

middle or served as a relief at the end of the class, often both. At the same time, the learners continued learning new words, definitions, spelling, pronunciation, etc.

Despite all the positive factors above, the classroom could not exactly recreate a reallife situation. However, the shuffling of games and activities ensured the learners' remained focused and their vocabulary and natural English was more enhanced as compared to the classes where language games were not introduced at all.

\section{Conclusion}

Games and similar activities familiarize learners with new vocabulary and conversational phrases and thus help them retain information more accurately and more quickly, they help develop learners' conversational abilities.

Games and activities encourage ESL learners to absorb words and phrases while having fun and enjoying their learning experience, particularly when such activities garner a friendly competitive environment which ensures the learners' interest and focus.

Games and activities therefore lead to a higher level of motivation among ESL learners as they are encouraging them to get involved and actively engage in activities and apply the language in simulated real life situations. The use of games and similar activities during classes motivated learners to continue their ESL studies on their own via mobile apps. Therefore, the study also proves that games are an excellent source of encouragement for ESL learners.

However, it has to be also acknowledged that there are many other teaching and learning methods that can be utilized and should not be ignored simply because fun games are being used.

\section{Recommendations}

Language games and similar classroom activities should be incorporated into everyday ESL learning environments for more effective learning and higher motivation of learners at all language proficiency levels. All the teachers should be given access to such activity materials. Benefits of using English language games and activities should be more clearly demonstrated to the educators.

\section{References:}

Byrne, D. (1987). Techniques for classroom interaction. New York: Longman.

Davies, P. \& Pearse, E. (2000). Success in English teaching. Oxford: Oxford University Press.

Dolati, R \& Mikaili, P. (2011). Effects of instructional games on facilitating of learners' vocabulary learning. Australian Journal of Basic and Applied Sciences, 5(11), 96-107.

Ellis, N.C. (1997). Vocabulary acquisition: Word structure, collocation, word-class, and meaning. In: N. Schmitt \& M. McCarthy (Eds.), Vocabulary: Description, acquisition, and pedagogy. Cambridge: Cambridge University Press.

Hadfield, J. (1990). Intermediate communication games. London: Nelson. 
Hunt, A. \& Beglar, D. (2002). Current research and practice in teaching vocabulary learning. In: J.C. Richard \& W.A. Renandya (Ed.). Methodology in language teaching: An anthology of current practice. Cambridge: Cambridge University Press.

Huyen, N. T. T., \& Nga, K. T. T. (2003). Learning vocabulary through games. Asian EFL Journal, 5(4), 90-105.

Lewis, M. (2006). Vocabulary acquisition through extensive reading. Cambridge: Cambridge University Press.

Paper submitted

Paper accepted for publishing

Paper published online
29 July 2020

06 October 2020

30 November 2020 